\title{
VÔOS MIGRATÓRIOS: PALAVRAS EM PÁSSARO, DE JOÃO GILBERTO NOLL
}

Marli de Oliveira Fantini Scarpelli Universidade Federal de Minas Gerais

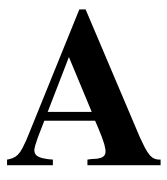

finado com as linguagens da contemporaneidade, João Gilberto Noll promove a interlocução do código verbal com outros sistemas semióticos no conto "O cego e a dançarina". Uma voz em primeira pessoa inicia o conto, discutindo os limites da ficção. Errante, desértico e estéril como "um pássaro mudo preso em gaiola", o sujeito da escrita enuncia a falência da narrativa e do processo de enunciação tradicionais. A imagem que enforma esse impasse é o revôo desenfreado de pássaros que deslizam por vácuos, espaços vazios e sem destinação. Sem alcance, os vôos e as palavras - como rizomas - condenam-se à irrefreável proliferação, à voragem da procura e à luta contra a dissolução. É assim que o conto não pára de circular em torno de um "fato cruento", de explicações que nunca explicam, de analogias que não fecham. A recursividade é o princípio estruturador dessa poética desterrante. Um vôo que revoa no sem-lugar duma "pátria sem fronteiras" é deslocado sempre pela voracidade de um eterno retorno em torno de um nada. O primeiro parágrafo do conto se ocupa em explanar os meios pelos quais o narrador-postagonista tentará sobreviver à volatização a que o obsoletismo de seu ofício construir narrativas e cenários que dêem conta de representar a vida em seu fluxo - o condena.

Sempre falei em pássaros. Azuis, amarelos, brancos, araras incolores. Súbito canto. Sempre falei num vôo que me parece demasiado. Não sei explanar melhor sobre isto porque aconteceu um fato que é mais voraz do que as

${ }^{1}$ NOLL, 1980. 
palavras em pássaro. Um fato que exaure todas as possibilidades.

O narrador tradicional de Benjamim trata exemplarmente das suas próprias e mais importantes vivências; sabe, ademais, receber e dar conselhos. A narrativa, que nasce da experiência pessoal de quem narra ou da relatada por outros, faz o objeto do conhecimento mergulhar na vida do narrador para depois retirá-la dele. A marca do narrador benjaminiano está impressa na narrativa assim como a mão do oleiro na argila do vaso. ${ }^{2}$

Diferentemente, o narrador de Noll não expressa vivências, e seu conto é destituído de epicidade. Mesmo porque tudo que se acha sob seu foco se esvai na imediatidade de pequenos e perecíveis flashes. O único suporte da narrativa é um olhar sobre o outro - um vôo cego lançado sobre cenas, fatos, corpos em movimento e, portanto, incapturáveis.

A afirmativa barthesiana de que a "literatura é o fulgor do real"3 parece encontrar homologia no texto de Noll. Porque consciente da impossibilidade de dar contorno às cenas, o narrador se vê condenado a um moto contínuo, ao eterno retorno do mesmo, recorrentemente reenviado ao mesmo cenário - o Restaurante Pathé, um restaurante de beira de estrada - "onde uma mulher dança continuamente ao som do mesmo mambo”. Sem experiência narrável, ele está fadado à repetição do mesmo que não se deixa fixar e não provoca a diferença desejada. Sem eira nem beira, este agônico narrador nada ganha nesse jogo de captura. Tudo se perde nessa poética de beira de estrada poeirenta e desértica.

Espacializados, os fatos não têm duração nem profundidade. E só existem enquanto objetos da enunciação, sendo, por isso, "cruentos" na percepção do narrador. Existindo somente na superfície reversível de um espaço instantâneo, com duração análoga ao fulgor dum lance de olhos, duma emissão de voz, dum dedilhamento pela máquina de

\footnotetext{
${ }^{2}$ BENJAMIN, 1987.

${ }^{3}$ BARTHES, 1978, p. 22.
} 
escrever, os fatos não ganham corpo ou consistência. O simultaneísmo de que o narrador lança mão, na tentativa de capturar o "sendo" do objeto da enunciação, resta como um simultaneísmo de linguagens. Que também falha enquanto tentativa de uma representação realista: "a mulher pensa que dança mas está apenas aturdida por vermes e o adolescente pensa que olha uma mulher que deseja mas de fato olha a mancha rosa suada que dança na sua quase cegueira" .

A multiplicidade do foco do sujeito do conhecimento em seus infindáveis desdobramentos; a imagética do interior sendo afetada pelo exterior; o (des)controle sobre o cenário e personagens, que, transmutantes, escapam ao dedilhar da máquina, fazem da narrativa um lugar de errância. O empenho do narrador logra tão-somente repetir a mesma música, a mesma cena, a mesma mancha - imagem da fugidia figura feminina - e a mesma cequeira do adolescente que escorre dos dedos do narrador para fulminá-lo com um tiro. Impotente diante dessa voragem que susta qualquer possibilidade de apreensão e fixação do objeto do conhecimento, o insciente sujeito do discurso reconhece a insuficiência de sua palavra enunciadora, que "se parece mais com a música do que com a comunicação verbal". O que atesta essa crudenta verdade é a sensação nítida de estar dizendo "em andantino, em presto, em adágio"5 Mas, como o dedilhar da máquina de escrever não acompanha o fluxo temporal da música, nem a simultaneidade com que o real opera os fatos, o narrador busca no cinema, na câmera cinematográfica, o amparo para, não representar, mas mostrar, pôr em cena o movimento, a musicalidade, a visibilidade, tais como operam dialogicamente no real.

O resultado é um desdobramento cênico, uma espécie de making off que fornece a imagem do constructo narrativo, do texto se fazendo; e que dá a ver a superposição de imagens especularizan-tes; a presença

${ }^{4}$ NOLL, 1980, p. 133.

${ }^{5}$ NOLL, 1980, p. 133. 
ainda de um narrador-cineasta encenando os fatos e tentando, ao mesmo tempo, exercer controle sobre a própria criação. Cenários dentro de cenários: arquitetura dialógica e inacabada, fazendo aparecer a crise da representação.

Esse artifício se instaura quando o narrador lança mão duma virtual câmera cinematográfica capaz de registrar o efêmero, os fluxos de pensamento, o dessensorializado, para cuja apreensão a sintaxe verbal é insuficiente:

Por isso de uns tempos para cá o cinema me tem seduzido tanto, pois ele não seria uma espécie de pele naturalista sem vôos musicais (embora tantos filmes neguem isso)? Queria olhar e registrar com uma câmera paciente que aguardasse os sinais visíveis dos vermes e da cegueira.

Enquanto o narrador fala do que procura, mas que não logra descrever, o objeto da enunciação desaparece de seu foco, produzindo o vácuo, a lacunidade no olhar, na voz, no corpo "pátria sem fronteiras": "Mas a dançarina verminosa e o adolescente cego desapareceram enquanto eu fiquei aqui matutando sofismas (...) O restaurante Pathé ficou para trás. E ficaram para trás os sofismas acerca das palavras em pássaro e da pele naturalista do cinema" . Dessa forma "o fato cruento" que tanto angustia o enunciador e do qual ele fala recorrentemente não refere o objeto da enunciação, mas antes a própria enunciação. Fere sobremaneira o narrador cuja falibilidade é metaforizada no tiro de misericórdia que lhe é desferido pelo protagonista - o adolescente bastardo e cego -, descontente com a ineficáfia desse seu pai textual.

As palavras são inoperantes para frear, no cenário móvel e dispersante da cena textual, o simultaneísmo e o desfreamento da cena vista-sentida-ouvida: "como confessei no início, as palavras em pássaros me atacam freqüentemente e voam sem deixar que a língua possa freá-las". ${ }^{7}$

A tentativa de superação do impasse criado com o uso do termo

${ }^{6}$ NOLL, 1980, p. 134. 
"pós-moderno" e seus derivados leva Lyotard ${ }^{8}$ a buscar uma terminologia adequada para um fenômeno que ele já vinha examinando desde outras suas incursões à arte e, mais especifica-mente, às narrativas desse final de milênio. "Re-escrita" da modernidade parecelhe um termo menos periodizado ou totalizante do que "pósmodernidade", quando se trata de dar especificidade às narrativas da contemporaneidade. Algo próximo da apreensão e do reconhecimento de um "sendo", que seja "aqui e agora", a coisa em si, alguma coisa da natureza do "das coisas que acontecem acontecendo", de Guimarães Rosa. Sem historicidade, sem liames apontando para intenções totalizantes. Lyotard trata duma face não esgotada da modernidade: não relembranças ou causas, mas o corte, o recorte, a reescrita perpétua, a escrita escrevendo-se a si mesma. Sem vínculos com valor, com lógica, sem compromissos. Algo como, segundo ele, as "micrologias" de Adorno, as "passagens" de Benjamin.

Como único fio condutor dessa linguagem, o filósofo sugere a associação livre, a "perlaboração" freudiana, recurso que, segundo ele, teria a capacidade de aliar aleatoriamente fragmentos de frase, pedaços de informação, unidades atomizadas, que se deixariam conduzir, não pela razão ordenadora, mas pelos sentimentos. Não haveria, nesse caso, resgate, nem análise, nem chance, portanto, para teleologias. Nessa poética, reescrever é registrar. É descrever enformando a cena enquanto ela se forma. Um "abrir-se a", deixando aparecer as coisas tais como se apresentam. Em lugar das grandes narrativas ou das metanarrativas, Lyotard contra ataca com a pequena narrativa. Certo de que o consensoé um horizonte que nunca se alcança, a ele contrapõe dissentimento. É assim que, insdispondo-se contra a legitimação do saber, as certezas, futurologias, determinismo, utopia, metafísica, paradoxos, fixidez, estabilidade, repetição, paradigmas tão caros às narrativas do século XIX, o filósofo propõe a paralogia, a

7 NOLL, 1980, p. 133.

${ }^{8}$ LYOTARD, 1989. p. 33-43. 
desestabilização do saber, os lances ou jogos de linguagem, o acaso, a incerteza, as pequenas narrativas, os fractais, tensões, mobilidade, instabilidade, diferença.

Recorto duas marcas dessa estética contemporaníssima: uma, na ordem da sintaxe, ou melhor, da parataxe: relações contíguas, cruzamento de unidades atomizadas, rendilhamentos abertos e abrindose em infindáveis fios aptos para novas texturas. Cenas, imagens, palavras paralelas, na sempre iminência de se tocar. Relação quase.

Uma outra marca - a deslinearização e a atopicidade resultantes da primeira - põe em crise noções como origem, identidade e representação. Crise que coloca o sujeito frente a frente com a imediaticidade. $\mathrm{Ou}$, como no dizer de Lyotard, sujeito em face de um "agora", que, arrastado pelo fluxo de consciência, pelo curso da vida e dos acontecimentos, "não pára de se dissipar". "

Penso nas cenas e palavras dançarinas de João Gilberto Noll. Emblematizadas no "mambo", que se repete indefinidamente, elas giram constelar e recorrentemente em torno de um não-lugar, de um sem-sentido, acabando por esvaziar-se na repetição. Repetição obviamente irônica, pois que a letra dessa música, ao colocar o sujeito enunciador naquele cenário desterrante - o sem-lugar da "pátria sem fronteiras" -, condena-o à estraneidade, ao exílio.

O mambo (...) tem uma parte que diz «venho ferido de uma pátria sem fronteiras". "Uma pátria sem fronteiras” é eu estar aqui quase esquecendo o que estou olhando e vendo uma paisagem que lembra o revolto Sul dos Estados Unidos num filme quem sabe de Elia Kazan sobre um roteiro de Tennessee Willians. ${ }^{10}$

O uso de música e de recursos filmicos dá um trato intersemiótico à construção narrativa. O revôo do pássaro é a imagem da enunciação, que, no inútil afã de capturar e traduzir o objeto do discurso, esbate-se fugidia em vôos vãos à volta de uma realidade inapreensível, incapturável, esvanescente. Consciente da precariedade e obsolescência de sua função

${ }^{9}$ LYOTARD, 1989, p. 33.

${ }^{10}$ NOLL, 1980, p. 134. 
enquanto voz narrativa e dos limites do código verbal, o narrador incorpora, à sua palavra - sempre esgueirante -, recursos sonoros, plasticidade, intermitências, mudança de foco, recursividade. E, no seu agônico expediente de dar a ver o fato representado, alia, à linguagem, recursos cinematográficos - relação analógica entre o olhar e a câmera, entre personagens/cenário/ação do conto e os de filmes emblemáticos da tradição hollywoodiana. O uso de uma câmera cinematográfica sinaliza a tentativa desesperada de capturar e transferir para o texto a "pele naturalista" da superfície filmica, pois, sem esse concurso, o narrador deste (meta)conto se sabe fracassado ou ineficaz na condução da cena ficcional.

Malgrado o empenho, as imagens e os fatos se esboroam no semlugar da "pátria sem fronteiras" do cenário ficcional, que, além de móvel e efêmero, se sabe - enquanto décor - construção artificial, em cuja superfície deslizante, a realidade não tem como se sustentar. A dissipação cênica á análoga à da linguagem. Pela percepção metapoética e desoladora do conto, o final dessa história de impotência do código verbal e da falibilidade dos procedimentos ficcionais equivale ao tiro desferido pelo adolescente no narrador. Este definha sem, contudo, perder a aguda conciência de que, sem o concurso de outros códigos - cinematográficos, sonoros, plásticos - estarão ele e sua narrativa condenados ao desaparecimento. Ou à morte, como sugere o desenlace do conto.

\section{Referências Bibliográficas}

BARTHES, Roland. Aula. Trad. Leyla Perrone-Moisés. São Paulo: Cultrix, 1978. p. 22.

NOLL, João Gilberto. O cego e a dançarina. Porto Alegre; São Paulo: L\&PM, 1980. 
BENJAMIN, Walter. O narrador. considerações sobre a obra de Nikolai Leskov. Obras escolbidas: Magia e técnica, arte e política. Trad. Sergio Paulo Rouanet. São Paulo: Brasiliense, 1987.

LYOTARD, Jean-François. Reescrever a modernidade. O inumano: considerações sobre o tempo. Trad. Ana Cristina Seabra e Elisabete Alexandre. Lisboa: Estampa, 1989.

\section{Resumo}

Afinado com a contemporaneidade, João Gilberto Noll promove a interlocução do código verbal com outros sistemas semióticos no conto "O cego e a dançarina" (1984). O revôo do pássaro, imagem recorrente de errância, tenta, inutilmente, cobrir espaços que, refratários a limites e fronteiras, migram continuamente, condenando à dissolvência o sujeito da enunciação e os fatos encenados. Consciente da precariedade da vOz narrativa e dos limites do código verbal, o narrador incorpora ao texto recursos sonoros e fílmicos, com cujo concurso, este (meta)conto conta para não se volatizar do cenário ficcional contemporâneo.

\section{Résumé}

João Gilberto Noll, écrivain représentatif de la littérature brasilienne contemporaine, mêle le code verbal et d'autres systèmes sémiologiques dans son conte"O cego e a dançarina". Le vol d'un oiseau, espèce de leit-motif y apparaît pour mettre en valeur les limites du narrateur et du langage littéraire, questions importantes qui les incrivent (le narrateur et la narrative) dans le panorame de la littérature d'aujourd'hui. 